\title{
Doxa y Paradoxa: el concepto de opinión pública en Ortega y el papel del filósofo
}

\section{Doxa and Paradoxa: the concept of public opinion in Ortega and the role of the philosopher}

"Dondequiera que haya habido sociedades poderosas, gobiernos, religiones, opiniones
públicas, donde haya habido, en fin, una tiranía, allí ha sido odiado el filósofo"

(Nietzsche, 2009: 43).

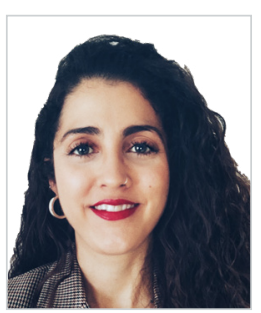

\begin{abstract}
Esmeralda Balaguer García. Doctoranda en el programa de Pensamiento Filosófico Contemporáneo de la Universidad de Valencia, Licenciada en Filosofía y Máster Universitario en Profesora de Educación Secundaria. Contratada FPI en el departamento de Historia, Teoría y Geografías Políticas de la Facultad de Ciencias Políticas y Sociología de la Universidad Complutense de Madrid. Directora de Nexofía, libros electrónicos La Torre del Virrey y miembro del consejo de redacción de la revista La Torre del Virrey. Revista de Estudios Culturales y de la Revista de Estudios Orteguianos. Sus campos de trabajo preferentes son la filosofía y el pensamiento español y la experiencia filosófica de exilio. Publicación más reciente: "La perspectiva del recuerdo: Proust desde Ortega", Alfinge. Revista de Filología, 31, (2019), pp. 9-29.

Universidad Complutense de Madrid, España

esmebala@ucm.es
\end{abstract}

ORCID: 0000-0002-5633-0565

Recibido: 30/01/2020 - Aceptado: 17/04/2020

Resumen:

El presente artículo trata de abordar la caracterología del concepto de "opinión pública" en el pensamiento político de José Ortega y Gasset. Hay varios tipos de opinión; Ortega no sólo habla de una "opinión pública", sino también de la "opinión particular" y entre ambas encontramos la "opinión verdadera". Frente a la doxa se analizará la paradoxa, es decir, la contra-opinión, suscitada por el filósofo. Si para la convivencia en una sociedad es esencial que haya opinión pública, será imprescindible dar cuenta del papel del filósofo en la construcción de esa convivencia.

Palabras clave:

Ortega; opinión pública; filósofo; vigencia; uso; poder público.
Received: 30/01/2020 - Accepted: 17/04/2020

Abstract:

This aim of this article is to approach the nature of the concept of "public opinion" in the political thought of José Ortega y Gasset. There are several types of opinion; Ortega not only speaks of a "public opinion", but also of an "individual opinion", and between both we find the "true opinion". In comparison to doxa, paradoxa will be analysed, which is in other words the concept of counteropinion raised by the philosopher. If it is essential to have public opinion in order for coexistence in a society to take place, it will be indispensable to consider the role of the philosopher in the construction of that coexistence.

Keywords:

Ortega; public opinion; philosopher; validity; use; public power.

Cómo citar este artículo:

Balaguer García, E. (2020). Doxa y Paradoxa: el concepto de opinión pública en Ortega y el papel del filósofo. Doxa Comunicación, 30, pp. 19-36.

https://doi.org/10.31921/doxacom.n30al 


\section{Introducción}

El concepto de "opinión pública" es un concepto complejo en la constelación orteguiana. Tratar de dilucidar qué quiso decir Ortega con este concepto es importante si queremos entender qué fue Europa y qué es Europa hoy para el propio Ortega. La opinión pública juega un papel principal en la filosofía política orteguiana porque es la fuente de donde emana el poder público. Ortega trató el tema de la opinión pública desde su juventud en varios escritos: en el artículo "De puerta de tierra” de 1912 que se publicó en El Imparcial, en “¿Quién manda en el mundo?”, en la segunda parte de La rebelión de las masas, y en varios escritos del exilio, tales como, "En cuanto al pacifismo...” del Epílogo para ingleses (1937), el libro inacabado de El hombre y la gente (1949-1950) y Meditación de Europa (1949). Estos cuatro últimos escritos, que nos permitirán delinear el carácter de la opinión pública, están estrechamente relacionados.

La publicación de La rebelión de las masas fue muy exitosa, no sólo en España sino también en otros países como Alemania, Francia o Estados Unidos. Uno de los países donde más éxito alcanzó y donde gozó de más reediciones fue en Estados Unidos, tal y como el hispanista Thomas Mermall hace constar en su estudio introductorio a La rebelión de las masas que preparó para Castalia. Fue uno de los libros más conocidos de Ortega y uno de los más traducidos y esto fue así porque el tema que allí aparecía tenía que ver con el creciente malestar de Europa, con "la pavorosa homogeneidad de situaciones en que va cayendo todo el Occidente" (Ortega, 2004-2010, t. IV: 352). La enfermedad que recorría Europa tenía que ver con el advenimiento de un nuevo tipo de hombre, el hombre-masa. Este hombre nuevo ponía en peligro la unidad europea porque todos sus principios, todos los usos europeos, le eran problemáticos y cuestionables, habían perdido su vigencia. Lo que empieza siendo una disección del carácter del hombre-masa en la primera parte de La rebelión de las masas concluye con la pregunta sobre quién ostenta el mando en Europa y qué caracteriza a una nación. La reflexión sobre Europa es uno de los temas principales en la segunda parte de La rebelión de las masas y en el "Prólogo para franceses" y el "Epílogo para ingleses", que Ortega escribió nueve años después para su traducción francesa e inglesa respectivamente. En 1949 Ortega dictó una conferencia en la Universidad Libre de Berlín que llevó por título Meditación de Europa, en la cual retomó muchas de las ideas que ya había planteado en "Quién manda en el mundo". Hay ocasiones en las que incluso reprodujo párrafos enteros con total literalidad. Quizás esto se deba a la idea que Ortega sostuvo, en "El Intelectual y el Otro" y en otros escritos, de que el intelectual se encuentra con todas las grandes ideas que va a desarrollar a la edad de 26 años, y a partir de entonces las madura y las mantiene hasta sus últimas consecuencias. En el "Prólogo para franceses”, Ortega apuntó que estaba componiendo el libro El hombre y la gente, donde realizaba un análisis sociológico y se adentraba en las profundidades del hombre, por tanto en ese momento sólo presentaba una primera aproximación al hombre actual.

El concepto de opinión pública está presente en estos tres libros porque es un concepto que permite vislumbrar el espíritu del propio tiempo. La opinión pública -escribió Ortega en "De puerta de tierra"- es la tonalidad de una época. La opinión pública es la más clara manifestación del espíritu de una época, del tipo de hombre predominante, del tipo de opiniones, ideas y preferencias. Si en esos escritos Ortega diseccionó al hombre y a la sociedad de su tiempo y examinó los problemas de Europa, era claro que no podía pasar por alto un concepto tan poderoso. La opinión pública, como veremos, es un sistema de usos verbales que emanan del decir de la colectividad y en la medida en que tienen vigencia 
se imponen al individuo. Si aquel que ejerce el mando quiere conservarlo, no podrá ir en contra de esta opinión pública, porque es el verdadero origen del poder público.

La pretensión de este artículo es la de trazar una radiografía de la opinión pública. Muchas son las preguntas que origina este concepto: quién es el sujeto de la opinión pública, qué fundamenta, en qué consiste su poder, cuánto dura en el tiempo, o dicho de otro modo, de qué depende su vigencia. Sea lo que sea la opinión pública, puede ser contraria a la opinión particular pero no necesariamente contraria, pues la opinión particular, ostentada por el filósofo hasta sus últimas consecuencias, debe ser la opinión que se filtre en el espíritu de ese tiempo y con el uso se corone como opinión pública. Este sería el mecanismo natural de la constitución de la opinión pública; esta debe manar de una opinión particular elaborada y en cierto modo "verdadera", en tanto que es la expresión del verdadero ser de las cosas. Todo esto será desarrollado en el apartado segundo.

El filósofo, como sostenía Nietzsche, nos educa contra nuestra época, contra la opinión pública, existe para que aprendamos a vivir con lo intempestivo de la vida y del pensamiento, para que el naufragio sea un movimiento natatorio constante y en la medida en que trata esto su vida corre peligro y, como señala la cita que abre este artículo, en consecuencia, es un hombre odiado. Este carácter del filósofo se asemeja a la figura del profeta que predica en desierto, figura a la que Ortega recurre en varias ocasiones y que está presente en el horizonte de pensamiento de los intelectuales de su época.

Podríamos perfilar la imagen del profeta para Ortega a partir de dos ideas: 1. "Un profeta 'pura sangre' no se contenta con menos que con poner las cosas del revés" (Ortega, 2004-2010, t. V: 614). O dicho de otro modo, el profeta-filósofo lo remueve todo y cuestiona todo. El profeta es profeta contra, sostiene Ortega, al igual que todo pensador. El profeta-filósofo lo es contra la "opinión pública"; 2. "Pero no hay destino más melancólico y más superfluo que el del profeta. Casandra, la primera profetisa, recibió de Apolo el don de prever el futuro y vaticinarlo con una condición: que nadie le hiciese caso" (Ortega, 2004-2010, t. VI: 947). El destino del profeta-filósofo es predicar en desierto, no ser escuchado e incluso ser odiado porque su tarea es la de aguijonear a todo aquel que se duerma frente su existencia. Ortega establece una clara distinción entre el profeta y el político, al igual que entre el filósofo y el político, pero insisto que profeta y filósofo son sinónimos en este contexto. Si el político manda y dirige a la muchedumbre, el profeta en cambio impera sobre las conciencias y administra la divinidad (Ortega, 2004-2010, t. III: 901). En La rebelión de las masas, Ortega vuelve a exponer esta distinción a propósito de la idea del profeta como consejero del político, o dicho de otro modo, para que el político pueda gobernar con rectitud es necesario que atienda a lo que el profeta-filósofo tenga que decir.

Eludo precisar a qué gremio pertenecían los profetas. Baste decir que en la fauna humana representan la especie más opuesta al político. Siempre será éste quien deba gobernar, y no el profeta; pero importa mucho a los destinos humanos que el político oiga siempre lo que el profeta grita o insinúa. Todas las grandes épocas de la historia han nacido de la sutil colaboración entre esos dos tipos de hombre. Y tal vez una de las causas profundas del actual desconcierto sea que desde hace dos generaciones los políticos se han declarado independientes y han cancelado esa colaboración (Ortega, 2004-2010, t. IV: 510).

Esta es una idea que ya encontramos en De Europae dissidiis et Republica, donde, el filósofo y humanista valenciano Juan Luis Vives, sostiene que el filósofo debe convertirse en el consejero del rey si quiere sobrevivir en la fauna humana. Vives 
será un filósofo muy importante durante el exilio de Ortega, pues durante esa dura etapa de silencio y de sentirse el extranjero perpetuo -si es que no lo sentía ya debido a su carácter de filósofo- se identificó con él.

La política necesita de la anticipación histórica, de la profecía que ofrece el filósofo, porque este está en condiciones de adelantarse al porvenir. Si el político no atiende a sus profecías, entonces el intelectual predicará en desierto

Hablar de la opinión pública es hablar de la doxa y el hombre que va contra la opinión pública, el hombre que genera la paradoxa, es el filósofo, o en palabras del propio Ortega, el intelectual. El título de este artículo trae una pareja de contrarios que viven en perpetua oposición. Frente a la opinión pública nos encontramos una opinión particular, que más allá de ser una mera opinión, se trata de la "opinión verdadera", de la opinión cargada de sabiduría porque esta ha sido meditada largamente y porque muestra el verdadero ser de las cosas.

Si la convivencia de toda sociedad depende de que exista la opinión pública, según sostuvo Ortega, debe haber una fuerza externa a esa opinión que suscite un malestar en lo habitual de los hombres, una opinión inteligente sostenida por el intelectual o filósofo. Recordemos que "inteligente" es una de las formas que procede de "elegancia", el elegante es el eligens, el que sabe elegir bien sus acciones. Ética y Elegancia son sinónimos. Este artículo va más allá de dar cuenta de la opinión pública, pues será una tarea incompleta si no nos preguntamos por el papel del filósofo en la construcción de esa opinión pública reinante.

\section{Doxa: el imperativo de volver a Platón}

A lo largo de la historia de la filosofía, muchos filósofos e intelectuales han meditado acerca de la opinión: desde Platón, con su distinción clásica entre doxa y episteme, hasta Walter Lippmann o Jürgen Habermas, quienes toman este concepto de "opinión pública" y lo desarrollan en sus libros La opinión pública, publicado en 1922, e Historia y crítica de la opinión pública, publicado en 1962, respectivamente.

Volver a la fuente de donde emana el concepto de doxa, esto es, hacer etimología, se torna un imperativo. Las palabras tienen una etimología no porque sean palabras, sino porque son uso. Para Ortega, el hombre es un animal etimológico. Constantemente hay que volver a Platón si queremos hacer filosofía y Ortega tenía presente esto. Platón fue un gran creador de lenguaje y dio sentido a las palabras ya usadas. Muchos de sus diálogos son intentos de definiciones. En $E l$ tema de nuestro tiempo, Ortega escribió: "así, en el orden intelectual, debe el individuo reprimir sus convicciones espontáneas, que son sólo 'opinión' - doxa-, y adoptar en vez de ellas los pensamientos de la razón pura, que son el verdadero 'saber' -episteme"- (2004-2010, t. III: 591). Ortega estaba haciendo una clara distinción, una distinción platónica: doxa y episteme no son en modo alguno lo mismo. La doxa nunca será conocimiento. Ortega sostuvo que la opinión es irreflexiva e irresponsable; la opinión pública no es objeto de enseñanza o de formación académica precisamente porque es doxa y no conocimiento verdadero sobre las cosas. Platón utilizó el concepto de episteme para distanciar el saber o conocimiento científico de otro tipo de saberes más sensibles o fenomenológicos como la doxa y la technéo arte. Recuerde el lector que episteme viene del verbo epistasthai, que significa "pararse sobre". Pararse y estarse en una creencia es un acto epistémico. La doxa, sin embargo, es un pensamiento y los pensamientos o las ideas, por utilizar la terminología orteguiana a la que posteriormente me referiré para distinguir la opinión pública de las opiniones particulares, se tienen y en la episteme o 
en las creencias se está y nos sostienen a nosotros. Si la opinión es un pensamiento que tenemos, cabe preguntarse qué papel juegan los conceptos de "verdad” y "perspectiva" en Ortega con respecto a la opinión. En 1916 Ortega escribía que "la realidad no puede ser mirada sino desde el punto de vista que cada cual ocupa, fatalmente, en el universo" (2004-2010, t. II: 163). Esto no quiere decir que la verdad sea relativa, sino que aun siendo una, solo puede conocerla el hombre desde su perspectiva, desde la posición particular y circunstancial que ocupa en el mundo. Toda doxa es el resultado de un posicionamiento vital en el mundo, pero que sea individual no la hace menos verdadera, porque representa una porción de verdad del mundo. El filósofo, en cambio, por ir contra la opinión sustentada en su propio tiempo, es quizás el que mayor verdad porte en su opinión precisamente porque es la que hace cuestionarlo todo.

Recuerde el lector aquel pasaje de La República donde Sócrates le pide a Glaucón que imagine una línea dividida en dos segmentos y cada segmento dividido a su vez en otros dos. El segmento inferior sería la doxa, compuesta por la eikasía (imaginación) y por la pistis (creencia) y designaría el interior de la caverna, aquello más alejado del verdadero conocimiento, la doxa sería un tipo de saber por medio del cual accedemos al mundo sensible. El segmento superior sería la episteme, compuesta por la diánoia (conocimiento discursivo) y la nóesis (inteligencia) y designaría el exterior de la caverna, el acceso al mundo inteligible, lo más próximo al sol, a la idea de bien, esto es, lo más próximo al saber.

Todos los hombres tienen opinión y además son partícipes de lo que Ortega llamó opinión pública, cuyo sujeto enunciador todavía no conocemos. Lo que cabe preguntarse en este punto es si todas las opiniones gozan del mismo valor. Esta reflexión servirá para dilucidar por qué la opinión pública disfruta de mayor valor que las opiniones particulares. Este valor no es cuantitativo, ni tiene que ver con una cuestión utilitaria, sino más bien de autoridad y de coacción sobre la población. La opinión pública domina el ambiente de una época y goza de una posición más elevada que el resto de opiniones particulares porque se constituye como la opinión reinante a medida que se usa de ella sin cuestionarla. Ese uso ejerce un poder y una coacción sobre las gentes para que siga siendo vigente y es en este sentido que goza de mayor valor (piénsese por ejemplo en nuestra costumbre o uso de llevar ropa cuando salimos a la calle, y este es un uso débil, pero piénsese en uno fuerte, una norma jurídica como la LOGSE de 1990 que promulgaba la obligatoriedad de la educación primaria y secundaria desde los 6 hasta los 16 años. En ambos casos esa "opinión pública" que se ha establecido con el uso ejerce una coacción en la gente para mantener su vigencia y en esta medida goza de mayor valor que las opiniones particulares).

A pesar de que la opinión no sea conocimiento, es arma harto poderosa. Fueron las opiniones de los hombres las que condenaron a muerte a Sócrates. Es muy significativo atender al diálogo del Critón. En él, Critón trata de persuadir a Sócrates de que huya de la ciudad antes de que la condena a muerte se ejecute, pero Sócrates trata de argumentar si con esa acción se le produce un bien o un mal a la ciudad a partir de la distinción entre la opinión de la mayoría y la opinión de los menos. Sócrates le pregunta a Critón por qué la opinión de la mayoría tiene tanta importancia y si es cierto que deben estimar las opiniones de unos hombres (las de aquellos hombres juiciosos) y no de otros. A través de la metáfora del gimnasta que debe cuidar su cuerpo y tiene en cuenta la opinión de su médico o entrenador antes que la opinión de la mayoría, Sócrates hace ver que debemos preocuparnos de la opinión de los menos y no tanto de la opinión de los más. La 
opinión de los pocos - aristoi- se contrapone a la opinión de los muchos - oi polloi-. ${ }^{1}$ Lo interesante del diálogo no es sólo esta contraposición, sino que Sócrates empieza hablando de la opinión de la mayoría y del conocedor de las cosas importantes, para terminar hablando de las leyes y de su obediencia a las mismas. ¿Son las leyes, únicas garantes del derecho, la expresión de la mayoría o de quien realmente sabe? Leo Strauss señaló esto bien en Estudios de filosofía platónica política. Las opiniones de los menos, que son útiles y buenas, deben ser estimadas en detrimento de la opinión de la mayoría. Pero, y esto es muy importante, "se debe considerar la opinión de la mayoría respeto de las cosas justas, nobles y buenas, y sus opuestos, no debido a su valor intrínseco, sino porque la mayoría tiene el poder de darnos muerte” (Strauss, 1985: 90).

Esta no es la concepción orteguiana de la opinión pública, pero tiene relación con esta idea. Ortega nos dirá que la opinión pública no tiene valor porque nos produzca temor y además temamos por nuestra vida, sino porque irremediablemente se nos impone. A esta imposición Sócrates la llamó “leyes”. Y esas leyes en Ortega vendrán a representar el derecho. Sigue resonando en el fondo la pregunta acerca de quién es el sujeto que dictamina las leyes.

\section{Carácter de la Opinión Pública}

"La opinión pública es la neblina, la tonalidad que envuelve y modula las opiniones todas de una época" (Ortega, 2004-2010, t. I: 552).

Si tomamos el Diccionario de filosofía de Ferrater Mora y acudimos a la voz "opinión”, encontramos que dice lo siguiente a propósito de la concepción platónica de la doxa:

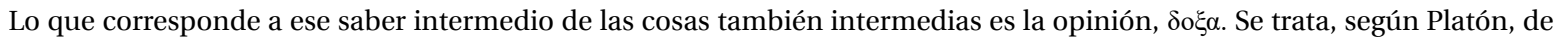
una facultad propia, distinta de la ciencia, de una facultad que nos hace capaces de "juzgar sobre las apariencias” (477 E). Como conocimiento de las apariencias, la opinión es el modo natural de acceso al mundo del devenir y, por lo tanto, no puede ser simplemente desechada. Sin embargo, lo que caracteriza al filósofo es el no ser "amigo de la opinión”, es decir, el estar continuamente abocado al conocimiento de la inmutable esencia. (...) En la opinión no hay propiamente un saber, ni tampoco una ignorancia, sino un modo particular de aserción (1982, t. I: 2.438).

1 Sobre la contraposición aristoi -oi polloi tenemos en el pensamiento orteguiano la oposición minoría-masa. En La rebelión de las masas Ortega nos hace notar que los conceptos masa-minoría no son sociales, no tienen un valor sociológico, sino antropológico. El binomio masa-minoría son funciones sociales, como señala Ignacio Sánchez Cámara (1986:49), son tipos de hombre. La masa es "el hombre medio", dice Ortega, que se siente como todo el mundo, que quiere imponer sus tópicos, que es hostil a la cultura, que vive una vida vulgar y descendente y cuyo atributo esencial es la inercia (Sánchez Cámara, 1986: 56). Las minorías, escribía Ortega, son los grupos de individuos especialmente cualificados, pero esta cualidad sobresaliente no estriba en sus pertenencias a una clase social elevada, sino a la capacidad de autoexigencia que la minoría ejemplar tiene. Dicho esto, Ortega concluye distinguiendo dos clases de hombres: "las que se exigen mucho y acumulan sobre sí mismas dificultades y deberes y las que no se exigen nada especial, sino que para ellas vivir es ser en cada instante lo que ya son, sin esfuerzo de perfección sobre sí mismas, boyas que van a la deriva” (2004-2010, t. IV: 378). Aquel que lleva una vida esforzada y excelente en cuanto a exigencias y aspiraciones, será el único capacitado para conducir al resto de hombres y por tanto de liderar la opinión pública. Ese es pues el papel de la minoría ejemplar para Ortega. El filósofo ya determinó la función de la minoría en un escrito de 1908 que llevaba por nombre De Re Politica (un título ciceroniano que apuntaba a la necesidad de salvaguardar la cosa pública): “Como del pueblo tiene que salir todo, es menester que salga también lo que no es pueblo: los escogidos. Del tesoro de su inconsciencia saca unas cuantas conciencias a quienes encarga de tener opiniones determinadas, únicas, particulares, ya que él es el conjunto de las opiniones reales y posibles, la opinión total, o lo que es lo mismo, la no-opinión. Porque opinar es tener 'una' opinión; quien tiene todas las opiniones es que no tiene ninguna. Toda opinión, pues, es siempre de origen privado y la única significación justa que puede tener esto de 'opinión pública' será la de opinión privad que se ha expandido, que ha sido inyectada en gran número de individuos" (2004-2010, t. I: 195). Siguiendo a Alejandro de Haro, del pueblo surge incluso lo que no es propiamente pueblo, sino su representación (2009:139). 
Esto nos dice varias cosas: la doxa es un saber intermedio entre la ignorancia y el conocimiento; un tipo de afirmación cercana al saber; un saber que no puede ser desechado porque permite el acceso al mundo cambiante; y, por último, si la doxa es todo eso, el filósofo no puede ser el amigo de la opinión, sino de la contra-opinión, de la paradoja.

Y continua Ferrater: “mientras la opinión individual es un acto intermedio, la opinión pública es un estado”. Esto resuena por todas partes a Ortega. En la opinión pública se está, no nos la cuestionamos porque ocupa todo el espacio público y se nos convierte en habitual. Hay dos ideas claras: la opinión pública jamás será conocimiento y el filósofo, que debe buscar la opinión verdadera, jamás será portador de la opinión pública.

Veamos ahora el carácter complejo que tiene el concepto de "opinión pública" en Ortega a partir de la respuesta a cuatro preguntas: ¿qué es la opinión pública? ¿qué fundamenta la opinión pública? ¿quién es el sujeto de esa opinión? y ¿durante cuánto tiempo es vigente?

Como respuesta a la primera pregunta acerca de qué entiende Ortega por opinión pública, en "De puerta de tierra”, un escrito de juventud, Ortega sostenía que la opinión pública es la tonalidad de una época. Tempranamente en su pensamiento, Ortega hacía constar dos cosas: que la opinión pública determina el espíritu de cada época y que esa opinión se constituye por la unión de la opinión de mayoría y minoría, dado que lo público reúne a ambas. Claramente Ortega estaba distinguiendo entre las opiniones particulares, que son de dos tipos, opiniones de la mayoría u opiniones de la minoría, y la opinión pública. A diferencia de las opiniones particulares que dependen del número de adeptos, la opinión pública no los necesita, no necesita ser declarada por muchos o por pocos. Es más, la opinión pública es la opinión latente que se esconde tras las opiniones particulares, de tal modo que "la opinión pública es la opinión que le queda a todo el mundo dentro" (Ortega, 2004-2010, t. I: 549).

Remito en este punto a la distinción orteguiana entre ideas y creencias para clarificar la noción de opinión latente a la par que pública. Es bien sabido que para Ortega en las creencias se está y las ideas se tienen. Las ideas son las opiniones particulares e individuales. Somos conscientes de ellas y tratamos de sustentarlas con razones y argumentos, hasta que dejan de convencernos y las cambiamos por otras. En cambio, las creencias son vigencias colectivas, que forman parte de nuestra cultura y que compartimos sin percatarnos de ellas. La misma estructura lingüística transmite estas creencias que laten en el sustrato último de toda sociedad. Estas creencias son la opinión pública.

Se presentan dos tipos de opiniones: las particulares, que se sostienen, se justifican razonadamente; y las opiniones "reinantes", que se dice de ellas que "todo el mundo las admite", y nos sirven para apoyarnos en ellas como un lugar común. No son propiamente ideas, en la medida en que no son fundamentalmente pensadas. Son tópicos que triunfan, no por su contenido, sino simplemente por ser uso, esto es, por la presión mecánica que se ejerce sobre todos los individuos (Peris Suay, 2018: 156-157).

La opinión pública se constituye como un uso, es decir, una acción acostumbrada y habituada y distinta de cualquier opinión particular. Los usos son la primera realidad con la que nos encontramos en la sociedad en la que vivimos. Para Ángel Peris Suay, "los usos, por tanto, no dependen de un pacto o un consenso social que supondría un alto grado de conciencia y actualidad, nacen de una minoría y se contagian a una mayoría a través de la influencia ejemplarizante” (2009: 236). Son hábitos sociales que no dependen de la frecuencia con la que sean ejecutados, sino de su carácter coactivo y de 
su capacidad para ejercer una presión moral. Cuando queremos hacer o dejar de hacer algo pero no podemos es porque el uso nos coacciona con un poder. Se trata del poder social (después veremos de dónde emerge este poder) que funciona con la coacción del uso. Sostiene Peris Suay que la opinión pública "por ser coactiva y presionante, reina y tiene poder. Es independiente del número de sus defensores" (2018: 157).

Para que el uso se constituya no es tan necesario un número determinado de adeptos, sino que sea "vigencia colectiva”. El carácter de la vigencia podría resumirse en lo siguiente: "lo que hacemos porque se usa no lo hacemos porque nos parezca bien, porque lo juzguemos razonable, sino mecánicamente lo hacemos porque se hace y, más o menos porque no hay otro remedio" (Ortega, 2004-2010, t. X: 281). Los usos son normas de conducta que hacemos inevitablemente.

Ortega distinguió dos clases de usos, cuya clasificación depende del grado de energía que haya en la coacción y de su resistencia a los movimientos de cambio histórico: por una parte, usos débiles y difusos; y por otra, usos fuertes y rígidos. A los primeros pertenecen los usos y costumbres cotidianos y el decir y el pensar de la gente. El decir de la gente se manifiesta en dos formas: la lengua y la opinión pública. Por tanto, la opinión pública para Ortega es un uso débil y funciona como un tópico, tiene que convertirse en algo viejo y no actual para ser uso. En cambio, el derecho y el Estado, dentro del cual aparece la política, serían usos del segundo tipo.

Para entender el uso "Estado”, también denominado por Ortega "poder público”, es necesario entender en qué consiste el sistema de usos intelectuales que Ortega llama “opinión pública”, es decir, el sistema de usos verbales que posee la lengua. La articulación de estos usos constituye la sociedad. En “En cuanto al pacifismo...”, Ortega señaló el proceso de constitución del derecho en tres fases: primero, algunos hombres ilustres encuentran algunas ideas o principios de derecho; posteriormente, hacen propaganda de esos principios en la colectividad (será vital dar cuenta del papel del filósofo en la última parte de este artículo para saber cómo puede introducir estas ideas en la sociedad); y por último, cuando la expansión de esas ideas de derecho sea predominante, entonces se consolidarán como opinión pública. Sólo cuando esto suceda se puede hablar plenamente de derecho como norma vigente. Si verdaderamente aquellas ideas actúan como normas de conducta, entonces tendremos derecho.

Para Ortega, la convivencia en la sociedad sólo es posible si hay usos intelectuales, esto es, opinión pública, porque esta dirige la conducta y la moral. Esos usos intelectuales son derecho (normas que se imponen a los individuos) y mantendrán su vigencia siempre y cuando el uso sea coactivo, o dicho de otro modo, siempre y cuando los individuos se sientan sometidos a la vigencia de ciertas opiniones. Ahora bien, cuando se abusa del uso o se convierte en desuso pierde su vigencia y por tanto todo su carácter de efectiva coacción.

Si, como he dicho, la opinión pública es un sistema de usos verbales, o dicho de otro modo, radica en el decir de la gente, entonces podemos distinguir dos tipos de opiniones siguiendo a Ortega: unas, las opiniones reinantes, son admitidas por todo el mundo; otras, las opiniones particulares, se enuncian sin ser admitidas. La clara diferencia entre ambas es que las opiniones reinantes son

Usos establecidos, y establecidos quiere decir que no necesitan del apoyo y sostén por parte de individuos o grupos determinados sino que, al revés, se imponen a todos, ejercen sobre todos su presión. Esto es lo que me lleva a denominarlas "vigencias". El vigor de esta vigencia lo percibe claramente, y con frecuencia enojosamente, el que intenta oponerse a ella. En 
todo instante normal de la existencia colectiva ejerce su vigencia un repertorio enorme de estas opiniones establecidas, que son los llamados “tópicos” (Ibid: 319).

Ortega las llamó "opiniones reinantes" porque su modo de estar en la sociedad se asemeja al del Gobierno. La opinión reinante lo será cuando sea más dominante que las demás, cuando sea vigente. Esta idea puede tener reminiscencias pascalianas. En el fragmento 311, sección IV, de sus Pensamientos, Pascal dijo lo siguiente: "el imperio fundado sobre la opinión y la imaginación reina durante algún tiempo, y este imperio es dulce y voluntario; el de la fuerza reina siempre. Así, la opinión es como la reina del mundo, pero la fuerza es su tirana". La fuerza a la que aquí se refiere Pascal no es la fuerza bruta, sino la fuerza que le otorga su estatus de estar por encima del resto de opiniones porque es predominante. Este carácter superior de la opinión pública Ortega lo llamó vigencia.

La diferencia radical entre la opinión pública y la opinión particular es que la primera es una opinión establecida y con vigencia y mientras conserva su vigencia, predomina e impera. En cambio, la opinión particular sólo existe en la medida en que alguien se tome el trabajo de sustentarla. El uso no es tal por la adhesión de los individuos, sino porque se impone a ellos. Sin embargo, es necesario que haya una adhesión consciente a la imposición, pues siempre cabe la posibilidad de ir en contra de la imposición, en contra del espíritu del tiempo.

Estas opiniones reinantes u opinión pública fundamentan el poder que la sociedad tiene frente al individuo, porque su poder, un poder que emana de la colectividad, es el poder público. El poder público es la intervención activa de la opinión pública y actúa sobre los individuos que integran la colectividad. Este poder actuará con mayor o menor violencia dependiendo de la importancia que la opinión pública le atribuya al abuso del uso. Para Ortega, la sociedad necesita el mecanismo del poder público para que actúe de forma violenta hasta que se haya creado el cuerpo estatal capaz de hacer funcionar el poder. Ese cuerpo estatal o poder político será el mando, afirmaba Ortega. Dicho de otro modo, el principio en que consiste el Estado es el poder público o social legitimado por la opinión pública.

Por lo tanto, esto daría respuesta a la segunda pregunta sobre qué fundamenta la opinión pública: la opinión pública para Ortega legitima el poder público y fundamenta el ejercicio del mando. Cuando Ortega escribió "Quién manda en el mundo" durante el período de entreguerras, Europa atravesaba una época de crisis histórica, en la cual quizá sigue imbuida todavía hoy, esto es, una época de crisis de creencias, donde todos los principios europeos, sus usos, derecho y opinión pública europea eran cuestionables y sus mandamientos habían perdido su vigencia.

En Europa, siguiendo la reflexión que presenta Villacañas, se había desarticulado la opinión pública porque el viejo sistema de equilibrio de poderes no podía operar, esto es, no podría ejercer el mando por más tiempo. La masa era la causante de esto pues

La homogeneidad europea se había refractado en diversidades y en el seno de cada nación una élite específica permitía la emergencia de una forma dada de la opinión pública cosmopolita. Sin embargo, cuando la homogeneidad europea era la masa, esta se refractaba en cada país también mediante una masa nacional. Ahora bien, esta figura impedía todo aliento cosmopolita y troceaba la opinión pública europea, de tal manera que nadie podía ejercer su poder unificador (Villacañas, 2011: 743). 
Frente a la desmoralización que sufría Europa, uno de cuyos síntomas fue el ascenso de las masas y el crecimiento que había experimentado la vida, ideas que se mantuvieron diecinueve años después en Meditación de Europa, escrita tras la Segunda Guerra Mundial y la Guerra Civil, se presentaba un problema mayor: Europa no estaba segura de ostentar el mando, porque no se sabía qué clase de hombre dominaba la opinión pública. Como advierte Javier Zamora "no siempre es la minoría selecta la que propone o impone sus gustos, sus tendencias, sus ideas, sino que hay periodos en los que predominan los gustos, tendencias e ideas vulgares, es decir, del pueblo, o se impone el hombre-masa" (2013: 102). Era imperativo saber quién mandaba en Europa para saber qué tipo de articulación iba a adquirir el poder. Esta fue una idea que Ortega retomó en Del Imperio Romano (1941). La concordia sólo es posible si sabemos claramente quien va a mandar y quién va a obedecer. Ortega afirmó que todo desplazamiento del poder implicaba un desplazamiento del espíritu. Antes ya quedó dicho que la opinión pública es el espíritu de una época. Por tanto, para comprender la Europa de su tiempo, Ortega sabía que la pregunta por el mando era inevitable.

A partir del siglo XVI se produce un proceso de unificación: quien manda ejerce su autoridad sobre el mundo. Europa ejerció la unidad de su mando hegemónicamente durante la Edad Moderna. Es importante que nos detengamos en el concepto de "hegemonía". Este concepto está vinculado al pensamiento de Gramsci. Para él, la hegemonía supone el control de las clases subalternas por parte de la clase dominante o hegemónica. Además, la clase dominante goza de hegemonía porque impone a la sociedad un sistema de usos bajo el cual se desarrolla la vida. Ortega también utiliza este término pero en un sentido distinto.

Para Ortega, el mando, que es el ejercicio normal de la autoridad, se ejerce hegemónicamente cuando se fundamenta en la opinión pública. La autoridad del mando no descansa en la fuerza -aunque pueda hacer uso de ella como un instrumento-, su hegemonía la consigue por medio de la opinión pública. Como Ortega sostuvo, no se puede mandar en contra de la opinión pública, porque el gobierno se sostiene y se crea por la opinión pública, y, por tanto, no puede ir en contra de esta.

A veces sucede que no hay opinión pública o hay discrepancias entre los grupos. Cuando la fuerza de la opinión pública está ausente, no da lugar al mando, y por tanto al poder público, sino a la fuerza bruta. ${ }^{2}$ El Estado, que es el equilibrio entre la opinión pública y el ejercicio tranquilo del poder por el mando, tiene que ver, en definitiva, con el estado de la opinión. "Mando significa prepotencia de una opinión; por tanto, de un espíritu; mando no es, a la postre, otra cosa que poder espiritual” (Ortega, 2004-2010, t. IV: 457). Es necesario que el tipo de espíritu que sea tenga el poder y lo ejerza para que la gente que carece de opinión pueda opinar. La mayoría de los hombres (hombre-masa) carecen de opinión y ésta ha de venirles de fuera (del mando).

Las minorías tienen un papel pedagógico esencial, tienen la tarea de conducir a la masa:

El pueblo no sabe lo que quiere, a lo sumo sabe lo que no quiere. Por eso hay que fomentar su opinión. Ésta ha de ser atractiva en grado suficiente. Pero el pueblo -la informe masa caótica de los muchos- no está capacitado para dirigirse. Esta función corresponde a lo que ya no es exactamente pueblo sino su representación (los mejores) (De Haro, 2009: 139).

2 El peligro político fundamental "es la escisión entre el poder público y la opinión pública que se plasmará en la continua pérdida de autoridad de las instituciones y, como consecuencia, la desintegración del poder político” (Peris Suay, 2018: 168). 
Las opiniones son necesarias para que la convivencia humana no sea un caos. Sin poder espiritual, o dicho de otro modo, sin alguien que mande, reina el caos. Por tanto, en cada época el mando descansa en la soberanía de la opinión pública, porque en el mundo siempre predomina un sistema de opiniones o usos.

Cabe preguntarse en este punto qué tipo de político o gobernante puede ostentar el mando que se sustenta en la opinión pública. Ortega distingue entre "el político", que hace una política menor y de superficie, y "el Político" o gran Político, en mayúsculas, que es capaz de escuchar la opinión pública y de sacarla a la luz, sin hacer prevalecer su opinión particular. Para Ortega

La verdadera opinión late: no se la ve, hay que descubrirla al través de sus efectos. Ahí tiene usted la genialidad del Político con mayúscula; la política minúscula es el juego de la superficie. El político opina sobre las cosas: el Político no opina por sí mismo, descubre en cambio con mirada de zahorí la opinión pública, la real, la eficaz y decisiva. Descubierta, la expresa, la saca a la luz y triunfa (2004-2010, t. I: 552).

El sujeto que formula la opinión pública -y con esto daríamos respuesta a la tercera pregunta sobre quien es el autor de la opinión pública- es una entidad impersonal, es todos y nadie determinado. Todo hombre vive bajo un determinado sistema de usos. Eso que hace se hace porque es lo acostumbrado. Y, ¿quién lo hace? La gente, aquel sujeto indeterminado que representa a la colectividad. La gente es ese "se" impersonal del español, o el "man" alemán, o el "on" francés. De pronto nos damos cuenta que en una gran porción de nuestras vidas hacemos y decimos lo que "se" hace y "se" dice. Es más, la mayor parte de nuestras ideas y opiniones las pensamos y las decimos porque "se" piensan y "se" dicen. Cuando hacemos y decimos lo que se hace y se dice, ese "se" impersonal lo llevamos dentro y lo somos. Muchas de mis acciones no nacen de mi voluntad, las hago porque es lo acostumbrado. Ortega puso el ejemplo del saludo. El acto de saludar a alguien es un acto que yo ejecuto, pero no lo hago voluntariamente, ni siquiera entiendo eso que tengo que hacer, lo hago porque es lo acostumbrado, de lo contrario me tomarían por maleducado. Es un acto que la gente repite y por eso lo hago. Saludar es una acción que está forzada por el uso y ese uso es el lenguaje. La lengua, que es un sistema de usos verbales, nos es impuesta al escuchar el decir de la gente. "El decir de la gente es, a la vez, un sistema de opiniones que la gente tiene, de 'opiniones públicas', es el inmenso conjunto de la opinión pública que nos penetra y se insufla en nosotros, casi nos llena por dentro y sin cesar nos oprime desde fuera (Ortega, 2004-2010, t. X: 268).”3

La opinión pública permanecerá vigente, como respuesta a la última pregunta que planteamos, siempre y cuando ejerza su poder coactivo y se imponga a todos. Para Ortega "nuestra opinión personal podrá ser contraria a la opinión social, pero ello no substrae a ésta quilate alguno de realidad. Lo específico, lo constitutivo de la opinión colectiva es que su existencia no depende de que sea o no aceptada por ningún individuo determinado (2004-2010, t. V: 318)." La opinión pública, al ser uso, no depende de mi adhesión a ella, sino que su vigencia depende de su carácter normativo o coactivo.

3 En este punto cabe destacar, siguiendo la tesis planteada por Ignacio Blanco, el papel que desempeñan los mass media en la formulación de la opinión pública. Sostiene que "este fenómeno de la mundialización o globalización de la vida del hombre medio está en estrecha relación con la irrupción de los medios de comunicación masivos en la contemporaneidad.” Apoyándose en Walter Lippmann, que también se había percatado del mismo fenómeno que Ortega vislumbró en La rebelión de las masas, esto es, el ascenso del nivel histórico y, por tanto, la subida del nivel de vida del hombre-masa, Blanco sostiene que los medios de comunicación tienen la imperiosa necesidad de influir en la conformación de la opinión pública y por tanto la necesidad de asumir esa función pedagógica (Blanco, 2018: 195, 196). Preguntémonos entonces si los medios de comunicación deben ser liderados por aquellos intelectuales que sepan acercar la verdad de las cosas al resto de hombres y que sean capaces de ir contra la opinión reinante. 
Una vigencia social presenta dos características según Ortega: es algo que está ahí y tenemos que contar con ella queramos o no porque se nos impone; y es una instancia de poder en la que podemos apoyarnos. Ortega señaló que la palabra "vigencia" procede de la terminología jurídica donde se distingue entre leyes vigentes y leyes abolidas. "Las vigencias -escribió Ortega- son el auténtico poder social, anónimo, impersonal, independiente de todo grupo o individuo determinado (2004-2010, t. X: 126)."

Con esto quedaría dibujado el carácter de la opinión pública. ${ }^{5}$ Pasemos ahora a tratar la misión del hombre que va en contra de esa opinión.

\section{Paradoxa. Misión del filósofo}

“Sorprenderse, extrañarse, es comenzar a entender. Es el deporte y el lujo específico del intelectual (2004-2010, t. IV: 376)”

En Miseria y esplendor de la traducción (1940) Ortega escribió:

Doxa significa la opinión pública, y no parece justificado que exista una clase de hombres cuyo oficio específico consiste en opinar si su opinión ha de coincidir con la pública. ¿iNo es esto superfetación o, como nuestro lenguaje español, hecho más por arrieros que por chambelanes, dice: albarda sobre albarda? ¿ No parece más verosímil que el intelectual existe para llevar la contraria a la opinión pública, a la doxa, descubriendo, sosteniendo frente al lugar común la opinión verdadera, la paradoxa? Pudiera acontecer que la misión del intelectual fuese esencialmente impopular (2004-2010, t. V: 714).

Habría que remontarse al inicio de la filosofía para entender esta cita en su totalidad. El movimiento filosófico comienza por sorprenderse y extrañarse de las cosas y va seguido del acto más importante, el aporein, esto es, problematizarse y problematizar a los otros, por eso Sócrates se denominaba a sí mismo como tábano en la Apología. Para Ortega, el intelectual tiene la ingrata e impopular misión de suscitar la paradoxa entre el resto de hombres. Su misión es la de forjar normas y principios que estructuren la sociedad. Por ello su ocupación "es opinar sobre todas las cuestiones importantes; pero al hacerlo lleva la contraria a la opinión pública. El intelectual opina contra la doxa vigente y, por tanto, se opone al pueblo”. Su misión, que entraña un grave peligro al que después me referiré, es "corregir la opinión pública y traer a los hombres del error en que están a la verdad que inexorablemente necesitan” (De Haro, 2009: 223).

La filosofía siempre nos mantiene delante de un abismo, nos hace batallar frente a constantes perplejidades y, por eso precisamente, es intempestiva y remueve hasta los cimientos más sólidos. Esa fue la tarea cartesiana, empezar todo de nuevo, reconstruir los cimientos del conocimiento desde el principio sin aceptar nada que antes no fuera cuestionado.

4 Mediante la razón histórica es posible rastrear el mundo de vigencias que impone la opinión pública a lo largo del tiempo, porque la historia para Ortega es el descubrimiento o alétheia de la realidad y de la vida pasada. La preocupación que Ortega tuvo por la historia siempre estuvo presente en sus escritos y el desarrollo de la razón histórica fue el tema principal de su segunda navegación. Su exposición filosófica de la razón histórica puede encontrarse en Historia como sistema. Para un estudio sobre la razón histórica puede consultarse el artículo de JAVIER ZAMORA Bonilla, "La razón histórica", Guía Comares de Ortega y Gasset, ed. de Javier Zamora Bonilla, Comares, Granada, 2013.

5 Para un estudio más pormenorizado sobre la opinión pública y su relación con la dialéctica masa-minoría véase la obra de ÁNGEL PERIS SuAY, Liberalismo y democracia en la obra de Ortega y Gasset, Biblioteca Nueva, Madrid, 2018. En el capítulo “El concepto de 'opinión pública', el autor sostiene que la cuestión de la opinión pública está presente en cuatro grandes problemas que planteó Ortega: 1. la opinión pública en relación con la función pedagógica de la política; 2 . la relación entre poder político y opinión pública en lo referente a la legitimidad del poder; 3 . la opinión pública en relación con el concepto político de nacionalización; 4. el problema que genera la imposición de la opinión de la masa. 
Cuando se explica por primera vez a los alumnos de un instituto qué suscita la filosofía, se dice que es asombro. Más bien no, no se trata de un deleite frente a eso que contemplamos, sino de una incomodidad. La filosofía nos pone frente a paradojas, frente a perplejidades y la tarea del filósofo debe ser la de suscitarlas, al tiempo que debe ofrecer ciertas ideas con las que los demás hombres puedan vivir frente a esas incertidumbres. Ortega hace notar, en El hombre y la gente, que quizás el título más acertado de un libro sea la Guía de perplejos de Maimónides, porque para Ortega la vida es una encrucijada y una perplejidad. Me atrevería a decir que la vida, en el sentido orteguiano, de realidad radical, es la primera perplejidad de la filosofía. Para Platón, la perplejidad era el origen mismo de la filosofía.

Se trata aquí de dar cuenta del deporte propio del intelectual, que es la paradoxa. Pero la paradoja no tiene lugar en un plano lineal, sino que es un trabajo de descenso y de ascenso. Ortega concede gran relevancia en sus escritos al papel del intelectual, un intelectual que debía estar comprometido con lo público, o dicho de otro modo, un intelectual que debía bajar a la caverna. Su propia figura fue la de un intelectual público, que denunció la política y la sociedad de su tiempo y además se comprometió fuertemente con todas las empresas que inició desde su juventud: con empresas periodísticas y editoriales, como Faro, España, El Espectador, El Sol, o Revista de Occidente; y con su actividad política. Ortega fue un filósofo que comprendió perfectamente que la tarea del verdadero filósofo no consiste en mantenerse en el mundo de las ideas, hay que bajar, la filosofía es un viaje de ida y de vuelta, una retirada para desvelar (alétheia) la verdad de las cosas.

La época del exilio, marcada por el silencio, le permitió a Ortega meditar largamente sobre la misión del intelectual, misión que se lleva a cabo en soledad y en perpetúa lucha contra aquel que no quiere ver, aquel que no quiere ser liberado de sus cadenas, el Otro, como el propio Ortega lo llama. "El Intelectual y el Otro" (1940), "El intelectual ante el mundo moderno" en La razón histórica (curso 1944) y "El especialista y el filósofo" en "En torno al Coloquio de Darmstadt” (1951), son reflexiones cultivadas en el momento del exilio sobre el papel del filósofo. Señala el profesor Javier Zamora que para Ortega "la misión del intelectual es elevar las cosas a la plenitud de su significado. A esto lo había llamado salvaciones en las Meditaciones del Quijote de 1914” (2004: 357). El intelectual, sostuvo Ortega, se hace cuestión de las cosas y se esfuerza por salvarlas, en cambio el Otro, que no es el intelectual, no se pregunta por la realidad de las cosas y ni siquiera es capaz de comprender que todas aquellas comodidades en las que se asienta su existencia en la caverna no están ahí sin más, sino que ha conllevado un esfuerzo de miles de años que sean así.

Ortega, que se preocupó por distinguir bien al Intelectual del Otro - del hombre-masa-, también se preocupó cuidadosamente de diferenciar la misión del intelectual de la del político. El político, que es un tipo de especialista, un hemipléjico porque su disciplina es parcial (en el prólogo a La rebelión de las masas Ortega sostiene que ser de derechas como ser de izquierdas son dos formas de hemiplejía moral), se empeña en confundir las cosas. La misión del filósofo es diametralmente opuesta a la misión del político: "la obra intelectual aspira, con frecuencia en vano, a aclarar un poco las cosas, mientras que la del político suele, por el contrario, consistir en confundirlas más de lo que estaban” (Ortega, 2004-2010, t. IV: 364). El filósofo trata de definir y de clarificar las cosas.

Para Ortega, el filósofo no es un especialista y mucho menos un profesional, el filósofo es un Denker o más bien, como sostuvo en el "Coloquio de Darmstadt" a propósito de una defensa de Heidegger, es un Zerdenker. El filósofo es un des- 
pensador y el buen Dios quiere que haya despensadores para que el resto de los animales no se duerman (aquí hay una clara referencia a la ciudad de los cerdos de Platón).

Si la tarea de la filosofía es la de generar paradojas que vayan en contra de la opinión pública vigente, ¿dónde tiene lugar

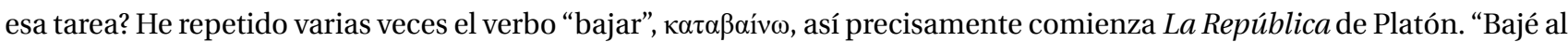
Pireo” -dice Sócrates-, esto es, a la ciudad. Dado que para Ortega la filosofía es una tarea de profundidades, es imperativo bajar.

La filosofía es siempre la invitación a una excursión vertical hacia abajo. La filosofía va siempre detrás de todo lo que hay ahí y debajo de todo lo que hay ahí. El proceso de las ciencias es progresar y avanzar. Pero la filosofía es una famosa "Anabasis", una retirada estratégica del hombre, un perpetuo retroceso. El filósofo camina hacia atrás (Ortega, 2004-2010, t. VI: 802).

Por tanto, la filosofía es un viaje de ida y vuelta, un descenso y un ascenso de la caverna porque es una tarea de profundidades y de superficie. El filósofo tiene la obligación de descender a las profundidades y sacar lo profundo hacia la superficie para hacerlo patente. Hacerlo patente significa hacerlo claro. Pero la claridad no implica librarnos de la paradoja, al contrario, supone ver con nuestros ojos la verdadera perplejidad que es la vida sin escondernos detrás de las sombras. Ya anuncié que esto entrañaba un peligro, un peligro que todos conocen de antemano, la impopularidad de la tarea del filósofo trae consigo la persecución. Esta persecución puede manifestarse de diversas formas, la cicuta para Sócrates, las persecuciones a Descartes, el exilio de Ortega, etc., con la intención de silenciar aquellos que están removiendo todo el suelo en el que cada cual basa su existencia. El intelectual, el filósofo, que es capaz de recogerse dentro de sí y de atender a su mundo interior cuando se queda en radical soledad, también es capaz de escuchar el decir que manifiestan las cosas a su derredor, porque las cosas por sí mismas no pueden relevar su propio ser, sino que sólo pueden decirlo. Este es el sentido que los griegos atribuían al logos, légein. Las cosas ponen su voz en el filósofo y esto para Ortega es un acto de inteligencia. La inteligencia es una opinión que arremete contra la opinión pública. Por eso el destino del filósofo es impopular, debe corregir la opinión pública, debe sacar al hombre de su error y acercarlo a la verdad. Su destino, decía Ortega, es áspero, bronco y terrible. La paradoja es una contra-opinión. ¿Por qué tiene validez la opinión del intelectual y no cualquier otra opinión?, cabe preguntarse. Precisamente porque la opinión del intelectual no es una opinión particular, sino más bien la Opinión Particular por excelencia y en mayúsculas, su validez reside en el acto de ensimismarse para dejar que las cosas hablen por sí mismas. Este acto es el paso inicial para desempeñar su tarea fundamental, la de llevar la contra a su tiempo, la de suscitar la duda sobre todas las cosas, incluso sobre aquellas más asentadas en nuestra cultura. El filósofo, que ha recorrido el camino del aprendizaje necesario para alcanzar la episteme, debe suscitar la contra-opinión. Esto legitima toda pretensión del intelectual de ir en contra de la opinión pública. Ortega escribió que "el intelectual comienza por hacer el vacío en sí mismo para dejar que en él se aloje y manifieste la verdad. Esto es lo que da sentido a ese revolverse del intelectual contra la opinión pública (2004-2010, t. IX: 651)”. Como el filósofo debe cuestionar los principios que acomodan al buen burgués, debe ser moderado y prudente, de lo contrario corre el riesgo de la persecución y la muerte. Ortega dijo en qué debía consistir esa moderación: la tarea del intelectual es la de oponerse y seducir. Una oposición cargada de seducción, esa era la clave. La filosofía no es otra cosa que un ejercicio erótico. 
Más pronto, el espíritu, la inteligencia comprendió que precisamente por ser el fondo de su misión oponerse a gigantescas fuerzas incoercibles, la forma de hacerlo no podía ser luchar con ellas, puño contra puño, sino, al revés, atraerlas, encantarlas, seducirlas. Ya que la inteligencia no tenga fuerza, déjesele que tenga gracia. Y, en efecto, a todo lo largo de la historia, la inteligencia ha sido o homenzinho da flauta que encanta a las cobras y dragones de la impulsividad. Después de todo, al hacer esto no hace sino imitar a Dios. O theós, el dios de Aristóteles es el ente supremo y primer motor del Universo. Pero no mueve al mundo con el dedo ni empujándolo como un ganapán. El primer motor mueve el mundo pero él mismo está inmóvil. Lo mueve atrayéndolo con su perfección, fascinándolo con su esplendor -y para aclararnos esta difícil idea Aristóteles emplea una de las metáforas más ilustres y agudas en la historia del pensamiento cuando dice que Dios mueve el mundo "como lo amado mueve a quien lo ama" (Ibid: 652).

El intelectual no puede luchar contra las pasiones, los apetitos o los intereses que el resto de hombres alberguen en su interior. Su forma de infiltrar su opinión es seducir y atraer esas fuerzas, esto es, filtrar las ideas que con el paso del tiempo y con el uso pasaran a convertirse en las creencias sobre las cuales se asiente la existencia, al igual que el dios aristotélico que lo pone todo en marcha sin moverse él mismo, siendo energeia.

\section{Conclusión}

$\mathrm{Si}$, para Ortega, una sociedad es la convivencia de hombres bajo la presión del sistema de usos vigentes, que son lugares comunes en el ideario colectivo, entonces de ello se desprende que quizás Europa todavía hoy sigue siéndonos problemática precisamente porque sus usos fuertes, los que tienen que ver con el derecho, las leyes y las normas de convivencia, no ejercen todo su poder coactivo y coercitivo. Esos usos tienen que ser vigentes e imponerse con toda su fuerza y legitimidad sobre la población para que sean verdaderos usos. Para ello, es imprescindible que se forme una opinión pública. Sin esta el ejercicio del poder público queda vacío. Es necesaria una opinión pública que sea norma y vigencia colectiva y esta vendrá de la capacidad que tenga el filósofo de infiltrar las verdaderas opiniones dentro de la colectividad. Doxa y paradoxa son dos polos que se atraen y se necesitan. El intelectual siempre deberá batallar contra las opiniones reinantes con el fin de introducir la opinión verdadera en el sistema de usos de la gente hasta que esta forme parte de la constelación de la opinión pública y de nuevo el intelectual tenga que combatirla. Pero frente a lo intempestivo de la vida, el hombre necesita una tabla de salvación y esta es la opinión pública, los usos, normas y vigencias con las que vivimos. ${ }^{6}$

Para iluminar esta reflexión, traigo a colación una cita del estudio introductorio de Nietzsche de los Diálogos platónicos:

Dos tipos de conocimiento: conocimiento racional (vovৎ) y recta opinión ( $\delta$ ó $\alpha \alpha$ á $\eta \theta \eta \varsigma)$. Son distintos, puesto que se originan de manera distinta: el primero, mediante enseñanza; el segundo, mediante persuasión; el primero, fundado; el segundo, infundado; el primero, no se deja conmover por persuasión; el segundo, se modifica mediante ella; del primero sólo los dioses y unos pocos hombres son partícipes; del segundo lo son todos los hombres (2013: 537).

6 Con el concepto de salvación me estoy refiriendo a la necesidad del hombre de estar asentado sobre ciertas "verdades" con las que vivir frente a la incertidumbre y a lo intempestivo de la vida. El hombre requiere de unas pocas creencias que le permitan realizar su vida y sobre las cuales se sienta seguro. El hombre necesita de certezas y la opinión pública es una de estas certezas que permiten al hombre ejecutar su vida alejado del sentimiento del desasosiego, por utilizar este adecuado término de Pessoa. 
Resalto precisamente esas dos últimas líneas. El acceso al conocimiento racional queda reservado a unos pocos y estos son los filósofos. Nietzsche casi parece comparar estos con los mismos dioses, como si el filósofo fuera un casi dios por tratar de alcanzar las verdades que habitan en los cielos. El otro tipo de conocimiento, el de la opinión, es accesible por todos los hombres. Es más, la opinión pública no sólo es un conocimiento alcanzable para todos, sino que, queramos o no, ejerce una presión sobre nuestras aspiraciones e ideas. Accedemos al conocimiento de la opinión pública porque ya está ahí, sin que nosotros tengamos que hacer ningún esfuerzo por llegar a él. En cambio, el conocimiento proveniente del nous sí requiere de un esfuerzo, necesita de la meditación, del ensimismamiento, de la reflexión solitaria y de la predisposición al aprendizaje y el dialogo que solo el filósofo está en condiciones de hacer.

$\mathrm{Si}$, como se ha sostenido, la opinión pública es un uso verbal para Ortega, es fruto del acto del hablar y del decir, del ejercicio lingüístico, entonces el filósofo debe descender a las profundidades del lenguaje para buscar el etymon de las cosas y oponerse a ese decir de la colectividad, que es la opinión pública.

Pero he aquí una paradoja: quizá la forma más idónea que la filosofía posee para que el filósofo seduzca, atraiga e infiltre sus ideas, sea el diálogo. El diálogo es un hablar entre dos o más y ese acto del habla usa de la lengua que ya estaba ahí, en el contorno social y que es fruto de la gente, que es manifestación de la opinión pública y que se aprende en el propio decir de la gente. El filósofo no está exento de caer en perplejidades. La lengua es un uso que se nos impone y nos coacciona y el filósofo tiene que abusar de ese uso, tiene que violentar el lenguaje, para, con el mismo uso, salir al encuentro de la opinión pública, que no es otra cosa que un uso verbal. Violentar el lenguaje significa aquí usar del lenguaje como un mero instrumento y abusar de él para expresar algo más profundo, el verdadero ser de las cosas. A esto Ortega lo llamó “Nueva Filología”. El abuso conlleva el peligro de la persecución y de la muerte, porque será la opinión pública, en la que vive inmerso el hombre común, quien decidirá cuanto abuso del uso es legítimo realizar. Por eso la tarea del filósofo siempre será impopular.

Ortega afirmó que el suelo desde el cual vive el hombre es la filosofía, aunque no lo adviertan. El filósofo o intelectual comprometido con su tiempo batallará contra la opinión pública vigente para que el color de los tiempos no sea el que es, para que el hombre, que vive adormilado en un sistema de usos que no cuestiona y que toma como la realidad misma, se haga cuestión de ellos. El filósofo es un Zerdenker y su tarea es la de despertar a las masas adormiladas en la caverna de la opinión pública.

\section{Referencias bibliográficas}

Blanco Alfonso, I. (2018). La crítica a la sociedad de masas y la función social del periodismo: José Ortega y Gasset y Walter Lippmann. En Aznar, H., Alonzo, E., Menéndez, M. (ed.), Ortega y el tiempo de las masas. Madrid: Plaza y Valdés.

De Haro Honrubia, A. (2009). La dialéctica masa-minoría en la filosofía de Ortega y Gasset: Contribución al análisis de las diferentes dimensiones que los conceptos "Hombre masa" y "Hombre minoría" adoptan a lo largo de la evolución del pensamiento orteguiano. Cuenca: Ed. de Castilla la Mancha. En línea: http://bit.ly/2TSdTU9.

Ferrater Mora, J. (1982). Diccionario de Filosofía. Madrid: Alianza Editorial. 
Nietzsche, F. (1954). “Schopenhauer als Erzieher”, Werke in drei Bänden, Band 1, herausgegeben von Karl Schlechta. München: Hanser. Traducción al español: Nietzsche, Friedrich (2009). Schopenhauer como educador, trad. de Jacobo Muñoz. Madrid: Biblioteca Nueva.

Nietszche, F. (2013). "Philologische schriften", Werke, Band 1, herausgegeben von Giorgio Colli et al. Berlín: De Gruyter. Traducción al español: Nietzsche, Friedrich (2013). “Escritos filológicos”, Obras completas. Madrid: Tecnos.

Ortega y Gasset, J. (1999). La rebelión de las masas, edición, introducción y notas de Thomas Mermall. Madrid: Castalia.

Ortega y Gasset, J. (2004-2010). “De puerta de tierra”, Obras Completas, tomo I. Madrid: Taurus/Fundación José Ortega y Gasset.

Ortega y Gasset, J. (2004-2010). “De Re Publica”, Obras Completas, tomo I. Madrid: Taurus/Fundación José Ortega y Gasset. Ortega y Gasset, J. (2004-2010). “Verdad y perspectiva”, Obras Completas, tomo II. Madrid: Taurus/Fundación José Ortega y Gasset.

Ortega y Gasset, J. (2004-2010). “Ideas sobre la novela”, Obras Completas, tomo III. Madrid: Taurus/Fundación José Ortega y Gasset.

Ortega y Gasset, J. (2004-2010). “El tema de nuestro tiempo”, Obras Completas, tomo III. Madrid: Taurus/Fundación José Ortega y Gasset.

Ortega y Gasset, J. (2004-2010). “La rebelión de las masas”, Obras Completas, tomo IV. Madrid: Taurus/Fundación José Ortega y Gasset.

Ortega y Gasset, J. (2004-2010). “En cuanto al pacifismo”, Obras Completas, tomo IV. Madrid: Taurus/Fundación José Ortega y Gasset.

Ortega y Gasset, J. (2004-2010). “Vives”, Obras Completas, tomo V. Madrid: Taurus/Fundación José Ortega y Gasset.

Ortega y Gasset, J. (2004-2010). "Las opiniones particulares de los hombres contra la fe de su tiempo son inauténticas”, Obras Completas, tomo V. Madrid: Taurus/Fundación José Ortega y Gasset.

Ortega y Gasset, J. (2004-2010). “Miseria y esplendor de la traducción”, Obras Completas, tomo V. Madrid: Taurus/Fundación José Ortega y Gasset.

Ortega y Gasset, J. (2004-2010). “Cultura europea y pueblos europeos”, Obras Completas, tomo VI. Madrid: Taurus/Fundación José Ortega y Gasset.

Ortega y Gasset, J. (2004-2010). “En torno al coloquio de Darmstadt”, Obras Completas, tomo VI. Madrid: Taurus/Fundación José Ortega y Gasset.

Ortega y Gasset, J. (2004-2010). “La razón histórica (curso 1944)”, Obras Completas, tomo IX. Madrid: Taurus/Fundación José Ortega y Gasset.

Ortega y Gasset, J. (2004-2010). “El hombre y la gente (curso de 1949-1950)”, Obras Completas, tomo X. Madrid: Taurus/ Fundación José Ortega y Gasset. 
Ortega y Gasset, J. (2004-2010). “De Europa Meditatio Quaedam”, Obras Completas, tomo X. Madrid: Taurus/Fundación José Ortega y Gasset.

Pascal, B. Pensées, IV, 311. Traducción al español: Pascal, Blaise (1981). Pensamientos, trad. de X. Zubiri. Madrid: Espasa-Calpe.

Peris Suay, Á. (2009). El concepto de opinión pública en el pensamiento político de Ortega y Gasset, Revista de estudios orteguianos, 18, 229-260.

Peris Suay, Á. (2018). Liberalismo y democracia en la obra de Ortega y Gasset. Madrid: Biblioteca Nueva.

Sánchez Cámara, I. (1986). La teoría de la minoría selecta en el pensamiento de Ortega y Gasset. Madrid: Tecnos.

Strauss, L. (1985). Studies in platonic political philosophy. Chicago: University of Chicago Press. Traducción al español: Strauss, L. (2008). Estudios de filosofía platónica política, trad. de Thomas L. Pangle. Buenos Aires: Amorrortu.

Villacañas Berlanga, J. L. (2011). Hacia la definición de un nuevo liberalismo. El pensamiento tardío de Ortega y Gasset, Arbor. Ciencia, Pensamiento y Cultura, vol. 178, 750, 741-754.

Zamora Bonilla, Ja. (2004). Los intelectuales y la crisis del Estado liberal en España. A propósito de la actuación pública de José Ortega y Gasset. En Baiôa, M. (ed.), Elites y poder. La crisis del sistema liberal en Portugal y España (1918-1931) (pp. 353-380). Lisboa: Ediciones Colibri - CIDEHUS.

Zamora Bonilla, J. (2013). La razón histórica. En Javier Zamora Bonilla (ed.), Guía Comares de Ortega y Gasset. Granada: Comares. 